\title{
Optimizing PEEP by Electrical Impedance Tomography in a Porcine Animal Model of ARDS
}

\author{
Nadine Hochhausen MD, Ingeborg Biener MD, Rolf Rossaint MD, Andreas Follmann, \\ Christian Bleilevens, Till Braunschweig MD, Steffen Leonhardt MD PhD, and \\ Michael Czaplik MD
}

BACKGROUND: Mechanical ventilation is necessary in diverse clinical circumstances. Especially in the context of ARDS, so-called protective ventilation strategies must be followed. It is already known that PEEP might enhance oxygenation in ARDS. However, determining the optimal PEEP settings in clinical routines is challenging. Electrical impedance tomography (EIT) is a promising technique with which to adjust ventilator settings. We investigated whether the combination of different EIT parameters, namely the global inhomogeneity and hyperdistension indices, may lead to a feasible and safe PEEP setting. METHODS: ARDS was induced by a double-hit approach in 18 pigs weighing, on average, $34.8 \pm 3.97 \mathrm{~kg}$. First, a surfactant washout was conducted; second, the tidal volume was increased to $20 \mathrm{~mL} / \mathrm{kg}$ body weight, triggering a ventilator-induced lung injury. Subsequently, pigs were randomized to either the EIT or control groups, followed by an observation time of $24 \mathrm{~h}$. In the control group, PEEP was set according to the ARDS network table. In the EIT group, a PEEP trial was conducted to determine an appropriate PEEP. At defined time points, hemodynamic measures, ventilation parameters, and EIT recordings, as well as blood samples, were taken. After euthanization, lungs were removed for subsequent histopathological and cytological examination. RESULTS: The combination of PEEP and $\mathrm{F}_{\mathrm{IO}_{2}}$ differed between groups, although respiratory compliance, gas exchange, and histopathological examinations, as well as hemodynamics, did not show any statistical differences between the EIT and control groups. However, in the control group, the PEEP/F $\mathrm{IO}_{2}$ settings followed the given coupling; in the EIT group, divergent individual combinations of PEEP and $\mathrm{F}_{\mathrm{IO}_{2}}$ ranges occurred. CONCLUSIONS: PEEP setting by EIT facilitates a more individual ventilation therapy. However, in our relatively short ARDS observation period of $24 \mathrm{~h}$, no significant differences appeared in common clinical parameters compared with a control group. Key words: ARDS; individualized mechanical ventilation; double-hit animal model of ARDS; electrical impedance tomography; global inhomogeneity index; hyperdistension index. [Respir Care 2017;62(3):340-349. (C) 2017 Daedalus Enterprises]

\section{Introduction}

Different lung pathologies resulting from pneumonia, aspiration, or trauma can lead to ARDS, which is a life-

Dr Hochhausen, Dr Biener, Prof Rossaint, Mr Follmann, Mr Bleilevens, and Dr Czaplik are affiliated with the Department of Anesthesiology; Prof Rossaint is also affiliated with the Department of Intensive Care; and Dr Braunschweig is affiliated with the Institute of Pathology, University Hospital RWTH Aachen, Aachen, Germany. Dr Hochhausen and Prof Leonhardt are affiliated with Medical Information Technology, RWTH Aachen University, Aachen, Germany. threatening complication ${ }^{1}$ with a mortality rate that exceeds $40 \% .^{2,3}$ Although there are different etiologies that lead to ARDS, the common final symptom is severe hypoxia. Therefore, the priority objective is to ensure ade-

\footnotetext{
Dr Czaplik was funded by grants from the Medical Faculty of RWTH Aachen University ("START", "Rotationsstelle"). Prof Leonhardt and Dr Czaplik have disclosed relationships with Dräger Medical GmbH (Lübeck, Germany). Prof Rossaint has disclosed relationships with CSL Behring, Bayer Healthcare, and Ingelheim Boehringer. The other authors have disclosed no conflicts of interest.
}

Drs Hochhausen and Biener contributed equally to this work. 


\section{Optimizing PEEP by EIT IN PoRcine ARDS}

quate oxygenation and avoid severe hypercapnia with mechanical ventilation. However, mechanical ventilation can simultaneously cause serious damage, such as edema, inflammatory processes, and atelectasis. ${ }^{4}$ Furthermore, the resulting inflammation can induce multi-organ failure, which also has a high mortality rate. ${ }^{5}$ To avoid these complications and, consequently, a progression of lung damage and consecutive organ dysfunction, protective lung ventilation that includes a tidal volume not exceeding $6 \mathrm{~mL} / \mathrm{kg}$ body weight and an airway pressure of $<30 \mathrm{~cm}$ $\mathrm{H}_{2} \mathrm{O}$ must be provided for critically ill patients. ${ }^{6,7}$ Furthermore, it is already known that the application of PEEP shows positive effects on gas exchange based on the opening or reopening of recruitable atelectasis. It is not as easy as it seems: An increased PEEP is not necessarily combined with a higher survival rate. ${ }^{8,9}$ In fact, it is essential to find the individual, optimal PEEP characterized by a balance ensuring recruitment and avoiding overdistention. One frequently used method to find optimal PEEP in a clinical routine is to increase PEEP step by step, followed by a check of the resulting oxygenation. The optimal PEEP is found when arterial oxygenation is highest. ${ }^{10}$ Although several alternative methods to optimize PEEP are already published, ${ }^{9-16}$ up-to-date individual ventilation therapy remains challenging.

So-called electrical impedance tomography (EIT) is a promising technique that recently became clinically available. It is a noninvasive, radiation-free, and bedside-available monitoring method that is adapted to visualize ventilation in time and spatial domains. ${ }^{17}$ Therefore, a number of electrodes (eg, 16 electrodes) that are attached to a belt must be placed around the chest. Several studies have already stated several clinical potentials and benefits of EIT. ${ }^{18,19}$ Since exact absolute impedances are difficult to measure, relative impedance changes, related to a reference, are usually used. However, by this means, functional EIT images, such as tidal variation images, can be created to show high correlations with inspired tidal volume and total air content of the lung. ${ }^{17,20}$

It is also known that EIT is able to monitor occurring atelectasis in the dorsal, gravitation-depending parts of the lung. Visualized impedance variation is "moving" ventralward. ${ }^{21}$ Furthermore, lung recruitment can also be visualized by EIT, in terms of contrary phenomena. ${ }^{22,23}$

Besides challenges in image reconstruction and the visualization methods that were addressed by diverse interdisciplinary working groups in past decades, the current

Correspondence: Michael Czaplik MD, Department of Anesthesiology, University Hospital RWTH Aachen, Pauwelsstrasse 30, 52074 Aachen, Germany. E-mail: mczaplik@ukaachen.de.

DOI: $10.4187 /$ respcare. 05060

\section{QUICK LOOK}

\section{Current knowledge}

PEEP setting in ARDS is still challenging. Electrical impedance tomography (EIT) is a bedside-available, promising technique to optimize ventilator settings. Different EIT-derived parameters have been studied, but none of them have yet entered clinical routine.

\section{What this paper contributes to our knowledge}

PEEP setting by EIT using a combination of the global inhomogeneity index and hyperdistension index is feasible and supports a more individualized ventilator therapy in a porcine model of ARDS. Furthermore, no statistically significant differences regarding respiratory parameters, hemodynamics, or cytological and histopathological examinations were observable compared with a conventional approach.

challenge is to establish EIT in clinical routines. Therefore, feasible and valid clinical EIT parameters or indices are required. In practice, intensivists and anesthesiologists need reliable data to adjust ventilator settings or to guide medical therapies. Up-to-date diverse parameters have been developed and published, ${ }^{21,23-25}$ of which none is yet established or clinically validated. Two of these newly developed parameters that concern the quantification of homogeneous ventilation are the global inhomogeneity index, which is based on image inhomogeneity, ${ }^{26}$ and the hyperdistension index, which quantifies alveolar hyperdistension, comparing compliances measured at different PEEP levels. ${ }^{23}$

Zhao et $\mathrm{al}^{26}$ demonstrated that a PEEP setting using the global inhomogeneity index is feasible in healthy lungs. In another study by our group, we found that using only the global inhomogeneity index to adjust the PEEP setting in a porcine model of ARDS can lead to severe complications. Obviously, high PEEP values that led to high inspiratory peak pressures were necessary to gain low global inhomogeneity indices. Consequently, barotrauma, overdistention, and further injury of lung tissue can occur as adverse events, counteracting major aspects of lung-protective ventilation. Limiting the maximum PEEP value, such as by using further parameters or limits, seemed to be essential. ${ }^{27}$ For that reason, the hyperdistension index was used. The aim of this study is to investigate whether it is possible to optimize the individualized PEEP setting by a combination of the global inhomogeneity and hyperdistension indices with regard to respiratory compliance, gas exchange, and histopathological examinations in a porcine animal model of ARDS. 
Optimizing PEEP by EIT In PoRcine ARDS

Table 1. ARDS Network Table for a Tandem Approach: PEEP and $\mathrm{F}_{\mathrm{IO}_{2}}$ Combination

\begin{tabular}{lllllccc}
\hline \hline $\mathrm{F}_{\mathrm{IO}_{2}}$ & 0.3 & 0.4 & 0.5 & 0.6 & 0.7 & 0.8 & 0.9 \\
$\mathrm{PEEP}, \mathrm{cm} \mathrm{H}_{2} \mathrm{O}$ & 5 & 6 & 9 & 10 & 12 & 14 & 17 \\
\hline
\end{tabular}

\section{Methods}

The study was approved by the North Rhine-Westphalia State Agency for Nature, Environment, and Consumer Protection (Germany; 84-02.04.2012.A173). In this pilot study, we included 18 female pigs (German Landrace) weighing, on average, $34.8 \pm 3.97 \mathrm{~kg}$. After the induction of anesthesia, the animals were intubated and mechanically ventilated (Servo 300, Siemens Elema, Solna, Sweden) with a tidal volume of $6 \mathrm{~mL} / \mathrm{kg}$ body weight, an inspiratoryexpiratory ratio of $1: 1, \mathrm{a} \mathrm{F}_{\mathrm{IO}_{2}}$ of 0.3 , and a PEEP of $5 \mathrm{~cm} \mathrm{H}_{2} \mathrm{O}$. In the supine position, femoral arterial and central venous catheters, as well as a pulmonary artery catheter, were placed. A continuous infusion of a balanced crystalloid solution $(0.1 \mathrm{~mL} / \mathrm{kg} / \mathrm{min})$ was started. During the whole investigation, analgesics (fentanyl, $0.1-0.2 \mathrm{mg} / \mathrm{h}$ ) and hypnotics (thiopental, $250-350 \mathrm{mg} / \mathrm{h}$ ) were administered according to humane clinical standards. Respiratory parameters, including the calculated Horowitz index, defined as $\mathrm{P}_{\mathrm{aO}} / \mathrm{F}_{\mathrm{IO}}$, as well as hemodynamic parameters and blood gas analyses were recorded continuously, monitoring the health of the animals. Catecholamine therapy and additional fluid management were initiated, if arterial blood pressure and urine production decreased, according to clinical routine.

After finishing the preparations, baseline measurements were performed. Thereafter, $\mathrm{F}_{\mathrm{IO}_{2}}$ was set to 1.0, and ARDS was induced by a double-hit approach. First, lavages with $30 \mathrm{~mL} / \mathrm{kg}$ body weight saline solution $(0.9 \%)$ were repeated every $10 \mathrm{~min}$, followed by blood gas analyses, until $\mathrm{P}_{\mathrm{aO}}$ was measured repeatedly $<100 \mathrm{~mm} \mathrm{Hg}$ for $1 \mathrm{~h}$. Second, pigs were ventilated with $20 \mathrm{~mL} / \mathrm{kg}$ body weight for $2 \mathrm{~h}$ with PEEP set to $0 \mathrm{~cm} \mathrm{H}_{2} \mathrm{O}$, aiming to provoke a ventilator-induced lung injury. ${ }^{28}$

After establishment of ARDS, animals were randomly assigned (Randlist 1.2., Dat Inf GmbH, Tübingen, Germany) to the EIT $(n=9)$ or control group $(n=9)$, and the investigation period started. Initially, $\mathrm{F}_{\mathrm{IO}_{2}}$ was set to 1.0 and PEEP to $21 \mathrm{~cm} \mathrm{H}_{2} \mathrm{O}$ in both groups.

Subsequently, hemodynamic measures, blood gas analysis, ventilation parameters, and EIT recordings were collected hourly up to $7 \mathrm{~h}$ after the establishment of ARDS and then every $2 \mathrm{~h}$ up to $24 \mathrm{~h}$ after ARDS. Additionally, blood samples were taken at defined time points (baseline and $0,5,12,18$, and $24 \mathrm{~h}$ after the establishment of ARDS) and centrifuged for $10 \mathrm{~min}$ at $2,500 \times \mathrm{g}$ at $4^{\circ} \mathrm{C}$. The resulting serum samples were immediately stored at $-80^{\circ} \mathrm{C}$ for subsequent analysis of

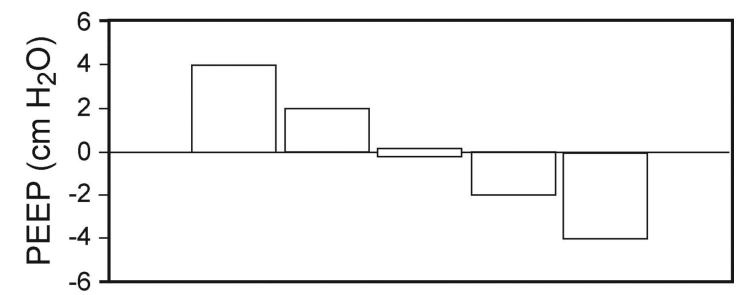

Fig. 1. Procedure for finding the optimal PEEP. In order to obtain the optimal PEEP, a stepwise PEEP increase and decrease was performed at each predefined time point in the electrical impedance tomography group.

interleukin- 6 and interleukin- 8 by using a magnetic beadbased multiplex assay (PCYTMAG-3K, Merck-Millipore, Darmstadt, Germany) and a flow cytometry-based analyzer (100/200 system, Luminex, Austin, Texas).

Based on the current $\mathrm{P}_{\mathrm{aO}}$ that was received from blood gas analyses, $\mathrm{F}_{\mathrm{IO}_{2}}$ was decreased by 0.1 when $\mathrm{P}_{\mathrm{aO}_{2}}$ was $>80 \mathrm{~mm} \mathrm{Hg}$ or 0.2 when $\mathrm{P}_{\mathrm{aO}_{2}}$ was $>100 \mathrm{mmHg}$ and increased by 0.1 when $\mathrm{P}_{a O_{2}}$ was $<55 \mathrm{~mm} \mathrm{Hg}$ or 0.2 when $\mathrm{P}_{\mathrm{aO}_{2}}$ was $<45 \mathrm{~mm} \mathrm{Hg}$. Thus, the target $\mathrm{P}_{\mathrm{aO}_{2}}$ was 55$80 \mathrm{~mm} \mathrm{Hg}$.

In the control group, PEEP was set according to the ARDS Network table (Table 1). In the EIT group, a PEEP trial was applied. Therefore, current PEEP (starting with $21 \mathrm{~cm} \mathrm{H}_{2} \mathrm{O}$ for $\mathrm{F}_{\mathrm{IO}_{2}}$ of 1.0) was first increased by $4 \mathrm{~cm} \mathrm{H}_{2} \mathrm{O}$. Afterward, PEEP was repeatedly reduced by $2 \mathrm{~cm} \mathrm{H}_{2} \mathrm{O}$, according to Zhao et al, ${ }^{26}$ until initial PEEP minus $4 \mathrm{~cm} \mathrm{H}_{2} \mathrm{O}$ was reached (Fig. 1). The maximum PEEP increase of $4 \mathrm{~cm} \mathrm{H}_{2} \mathrm{O}$ was chosen to limit the maximum PEEP level to $25 \mathrm{~cm} \mathrm{H}_{2} \mathrm{O}$ and with this the maximum peak inspiratory pressure to $40 \mathrm{~cm} \mathrm{H}_{2} \mathrm{O}$. At each point in time, an EIT sequence of $1 \mathrm{~min}$ and the above-mentioned hemodynamic and respiratory measures were recorded. In this study, the Dräger EIT Evaluation Kit II and Data Review 5.0 software (Dräger Medical, Lübeck, Germany) were used for acquisition and image reconstruction by using a 16-electrode belt that was fastened around the thorax in projection to the 5th and 6th intercostal spaces. The tidal variation images of $32 \times 32$ pixels in size were generated using the reconstruction algorithm provided by the aforementioned Dräger software. Each pixel of these tidal images represents the impedance difference between end-inspiration and end-expiration. Based on these images, the global inhomogeneity and hyperdistension indices were calculated using a self-developed MATLAB program (MATLAB 2013a, The MathWorks, Natick, Massachusetts). The global inhomogeneity 


\section{Optimizing PEEP by EIT IN PoRcine ARDS}

index was calculated from tidal images as introduced by Zhao et al. ${ }^{29}$ To do so, the median value of each tidal image was calculated. Then absolute differences between the median value and every pixel value were summed up and normalized by dividing by the sum of all pixel values. ${ }^{29}$ As introduced by Costa et $a l,{ }^{23}$ the hyperdistension index is calculated by computing pixel compliance at every PEEP step. Then the relative change in compliance to its best compliance is calculated pixel-wise. The hyperdistension index represents the mean of these values over all pixels. ${ }^{23}$

The global inhomogeneity and hyperdistension indices were calculated for each PEEP step, where the hyperdistension index referred to the initial PEEP level before starting the PEEP trial. Optimal PEEP was defined when the global inhomogeneity index was lowest, provided that the hyperdistension index was $\leq 10 \%$. Apart from that, the next higher global inhomogeneity index was accepted, fulfilling this condition. For further analysis, the impedance ratio was determined. This parameter is defined as the ratio of the impedance variation of the ventral half of the lung section divided by its dorsal half. ${ }^{30}$

Twenty-four hours after the presence of ARDS, animals were sacrificed under deep sedation, including a bolus of pentobarbital of $0.5-1 \mathrm{~mL} / \mathrm{kg}$. Afterward, the lungs were removed, photograph-documented, and examined. In doing so, lungs were anatomically sectioned into their lobes. For cytological analysis, a bronchoalveolar lavage was conducted from the right lower lobe. The accumulation of granulocytes, lymphocytes, and macrophages was assessed. Lung tissue samples for histopathological analysis were taken from the left upper and lower lobe so that a senior pathologist could analyze 2 peripheral regions and one central region. The examination was targeted on lung edema (interstitial and alveolar), infiltration of granulocytes and macrophages, and aspect of hemorrhage. Therefore, a semiquantitative assessment was used, ranging from minor to major in 3-6 steps. Moreover, ventral and dorsal tissue samples were taken from the right upper and middle lobes for analysis of wet/dry ratio.

Statistical analysis, including the Kolmogorov-Smirnov test and Mann-Whitney U test, were performed by SPSS 22 (SPSS, IBM Business Analytics Software, Armonk, New York). All tests were 2-tailed. Statistical significance was considered for $P<.05$. Due to the pilot nature of this study, no power analysis was performed. To compare predefined outcome parameters of the EIT and control groups with each other, medians and quartiles over time after establishing ARDS were calculated.

\section{Results}

All animals included in this investigation were in good health, as confirmed by veterinary examination. After con- ducting the aforementioned double-hit procedure, all animals suffered from ARDS. Five animals ( $n=3$ of the EIT group; $n=2$ of the control group) did not survive the entire study. Three of them belonged to the EIT group and died between 11 and $19 \mathrm{~h}$ after fulfilling the criteria of ARDS; 2 control animals died 17 and 19 h, respectively, after ARDS.

The PEEP settings differed between groups (Fig. 2). In the control group, due to the given fixed coupling, higher $\mathrm{F}_{\mathrm{IO}_{2}}$ values led to higher PEEP levels and vice versa. In contrast, in the EIT group, this dependence dissipated. High PEEP levels were used at high $\mathrm{F}_{\mathrm{IO}_{2}}$ values, as well as at low $\mathrm{F}_{\mathrm{IO}_{2}}$ levels. In detail, the EIT group included some animals that show a most homogeneous ventilation at PEEP levels $<10 \mathrm{~cm} \mathrm{H} \mathrm{H}_{2} \mathrm{O}$, although $\mathrm{F}_{\mathrm{IO}_{2}}$ was $>0.8$. Additionally, some animals showed the best relationship between hyperdistension and alveolar collapse at PEEP levels that were $>15 \mathrm{~cm} \mathrm{H}_{2} \mathrm{O}$, although $\mathrm{F}_{\mathrm{IO}_{2}}$ was $<0.4$. In contrast to the conventional approach, even in the middle range of $\mathrm{F}_{\mathrm{IO}_{2}}$, the resulting PEEP settings varied individually.

The global inhomogeneity index of the EIT group differed significantly from that of the control group (26.67 vs $26.21, P=.002$, EIT vs control group). Additionally, the impedance ratio was lower in the EIT group (1.63 vs 2.85 , $P<.001$ ), which indicates a shift of ventilation from the ventral part to the dorsal, dependent part of the lung.

The pathological examination attested to signs of lung edema, atelectasis, hyperdistension, and pneumonia in all tissue samples. Therein, neither the aspects of interstitial and alveolar edema $(P=.16$ and $P=.26)$ nor wet/dry ratio (5.9 vs $5.5, P=.26$ ) were different. All other pathological and biochemical examinations failed to show any statistical differences (Table 2).

No statistical differences occurred between the EIT and control groups regarding respiratory mechanics, gas exchange, hemodynamics, and histopathological examinations during the investigation period after the presence of ARDS. Neither median compliance over time $(8.94 \mathrm{~mL} / \mathrm{cm}$ $\mathrm{H}_{2} \mathrm{O}$ vs $9.44 \mathrm{~mL} / \mathrm{cm} \mathrm{H}_{2} \mathrm{O}, P=.80$, EIT vs control group) (Fig. 3) nor Horowitz index (171 vs $149 \mathrm{~mm} \mathrm{Hg}, P=.73$ ) (Fig. 4) or PEEP (10 vs $9 \mathrm{~cm} \mathrm{H}_{2} \mathrm{O}, P=.73$ ) (Table 3) differed between groups.

For further analysis of the highly variable individual PEEP levels, a subgroup analysis was conducted. Therefore, the EIT group was divided into 3 subgroups for further analysis: subgroup A, in which PEEP level was $>3 \mathrm{~cm} \mathrm{H}_{2} \mathrm{O}$ lower than expected regarding the reference value from the ARDS Network table; subgroup B, in which PEEP was equal to or similar to the reference value; and subgroup $\mathrm{C}$, in which PEEP was $>3 \mathrm{~cm} \mathrm{H}_{2} \mathrm{O}$ above the reference value.

There were no differences regarding hemodynamics except for the heart rate. It was increased in subgroup A as compared with subgroup B (128 vs 113 beats/min, 


\section{Optimizing PEEP by EIT IN PoRcine ARDS}
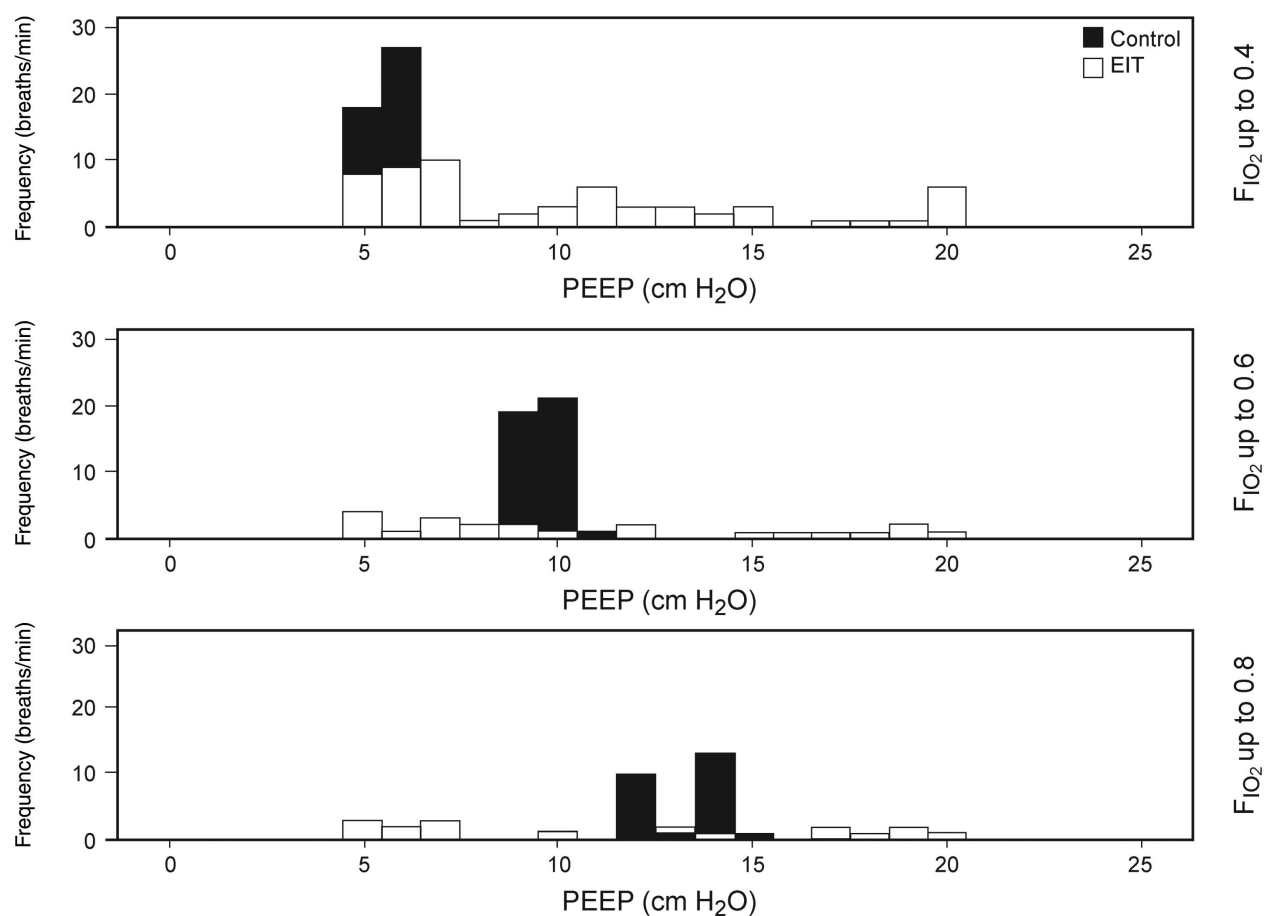

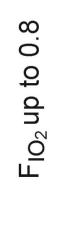
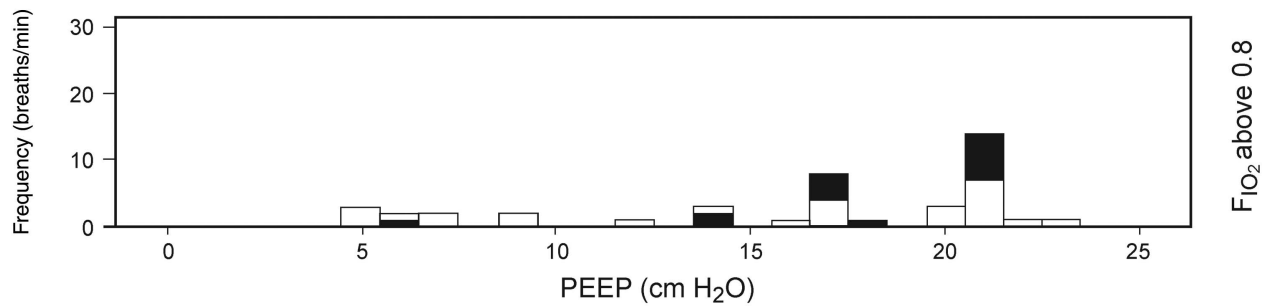

Fig. 2. The PEEP level shows a strict dependence in the control/conventional group. A high PEEP level was associated with high $\mathrm{F}_{1 \mathrm{IO}_{2}}$ values; conversely, a low PEEP level was associated with low $\mathrm{F}_{\mathrm{IO}_{2}}$ values. In contrast, no strict dependence in the electrical impedance tomography (EIT) group was observable.

$P=.003)$. Horowitz indices differed between all subgroups (73 vs $157 \mathrm{~mm} \mathrm{Hg}[P<.001$; subgroup A vs B] and 347 vs $157 \mathrm{~mm} \mathrm{Hg}[P<.001$; subgroup $\mathrm{C}$ vs $\mathrm{B}]$ ).

Results from histopathological analysis did not differ. Obviously, higher PEEP levels led to higher oxygenation indices. However, even in subgroup A, our predefined target range was achieved.

\section{Discussion}

In this study, it was shown that an EIT-based PEEP setting is feasible and led to more individuality than a conventional clinically established approach. Therefore, an EIT-based procedure using the global inhomogeneity index and hyperdistension index was developed. When following this procedure, a fixed coupling between $\mathrm{F}_{\mathrm{IO}_{2}}$ level and PEEP setting that appeared in the control group did not arise in the EIT group. In fact, in EIT group, different combinations of $\mathrm{F}_{\mathrm{IO}_{2}}$ and PEEP occurred. No differences were identifiable with respect to predefined clinical outcome parameters, such as respiratory compliance, gas exchange, and histopathological examinations. Additionally, EIT, as a bedside monitoring technique, allows for the diagnosis of atelectasis, pneumothoraxes, or other complications in real time.

Lung-protective ventilation with low tidal volumes is known to be beneficial in patients with ARDS, but the optimal PEEP level remains uncertain. Several common clinical approaches for PEEP optimization are described in the literature, but only oxygenation as a target has become accepted in clinical routine. Thus, the ARDS network table, which contains relatively fixed combinations of $\mathrm{F}_{\mathrm{IO}_{2}}$ and PEEP, is commonly used at the bedside, although individual lung mechanics are not considered.

In contrast, another approach, which brings lung mechanics into focus, is the compliance method that is based on a PEEP trial by selecting the PEEP with the highest compliance. ${ }^{10,11}$ Another alternative possibility with which to find the optimal PEEP is to perform a slow-flow inflation maneuver to assess a pressure-volume curve, which 


\section{Optimizing PEEP by EIT IN PoRcine ARDS}

Table 2. Histopathological Findings and Biochemical Results

\begin{tabular}{|c|c|c|c|}
\hline Histopathological Findings & EIT & Control & $P$ \\
\hline Wet/dry ratio & $5.9(4.3-7.2)$ & $5.5(2.4-6.4)$ & .26 \\
\hline Interstitial edema, score & $2(2-2.5)$ & $2(1.5-2)$ & .16 \\
\hline Alveolar edema, score & $2(2-2.5)$ & $3(2-3)$ & .26 \\
\hline Infiltration of granulocytes, score & $3(2-3)$ & $3(3-3)$ & .44 \\
\hline Infiltration of macrophages, score & $2(2-2)$ & $1(1-2)$ & .30 \\
\hline Hemorrhage, score & $1(1-4)$ & $1(1-3)$ & .86 \\
\hline Aspect of atelectasis, $\%$ & $20.0(5-20)$ & $10.0(7.5-20)$ & .86 \\
\hline Aspect of emphysema, $\%$ & $20.0(5-20)$ & $10.0(7.5-30)$ & .39 \\
\hline Aspect of pneumonia (peripheral region 1), \% & $10.0(5-25)$ & $30.0(10-55)$ & .08 \\
\hline Aspect of pneumonia (peripheral region 2), \% & $90.0(60-90)$ & $70.0(40-85)$ & .26 \\
\hline Aspect of pneumonia (central region 1 ), $\%$ & $80.0(60-90)$ & $60.0(30-85)$ & .19 \\
\hline BAL granulocytes, $\%$ & $60.0(25-75)$ & $50.0(35-70)$ & .82 \\
\hline BAL lymphocytes, \% & $20.0(10-20)$ & $10.0(10-27.5)$ & .82 \\
\hline BAL macrophages, $\%$ & $20.0(15-50)$ & $25.0(20-37.5)$ & .74 \\
\hline Interleukin-6, pg/mL & $226(163-268)$ & $210(196-731)$ & .80 \\
\hline Interleukin- $8, \mathrm{pg} / \mathrm{mL}$ & $118(84-202)$ & $86(49-129)$ & .22 \\
\hline
\end{tabular}

Results are medians (interquartile range). Shown are results from histopathological examination including wet-to-dry ratio; diverse semiquantitative scores for comparing edema, cellular infiltration, and hemorrhage; and aspects of atelectasis, emphysema, and pneumonia in different regions in percentage. Second, examination findings from bronchoalveolar lavage are shown. Third, biochemical analysis results are provided.

EIT $=$ electrical impedance tomography

$\mathrm{IQR}=$ interquartile range

$\mathrm{BAL}=$ bronchoalveolar lavage

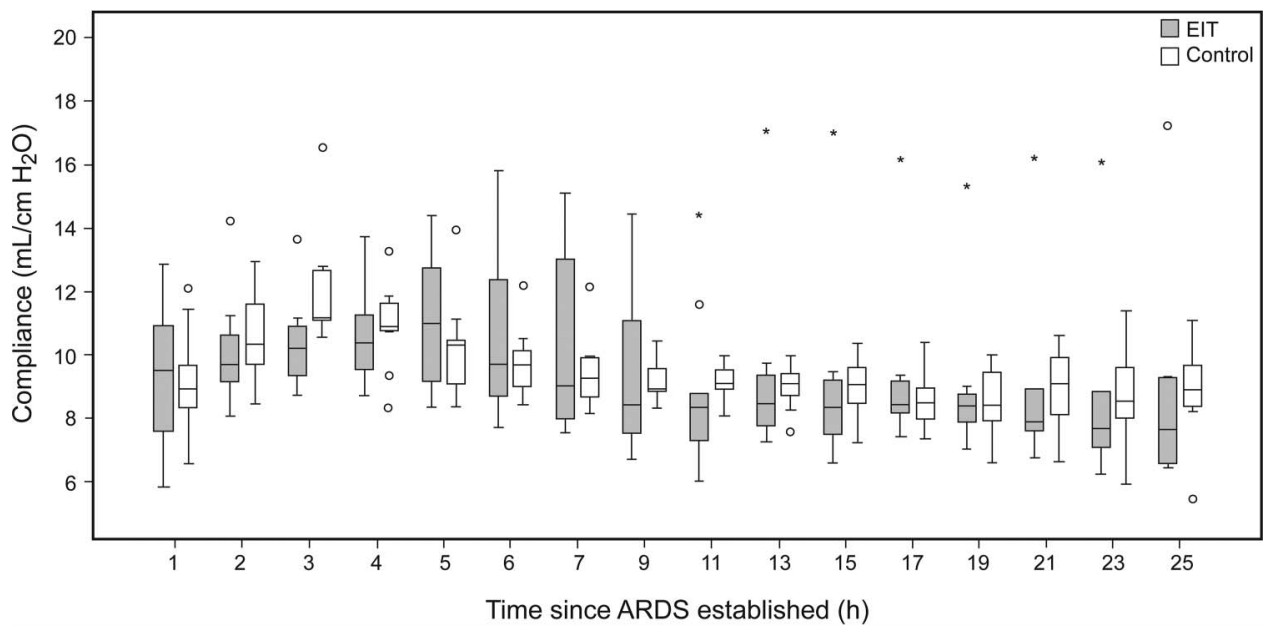

Fig. 3. Course of respiratory compliance over time. After the establishment of ARDS, respiratory compliance was significantly reduced, and stability was maintained during the entire investigation in both groups. Boxes represent interquartile ranges, and center lines denote the median. Whiskers show the highest and lowest values. Outliers are shown as points; extreme outliers are shown as stars. EIT = electrical impedance tomography.

takes a sigmoidal course with 2 noticeable marks: the upper and the lower inflection points. The ventilation parameters PEEP and inspiratory peak pressure should range between the upper and lower inflection points. Setting the PEEP by using the pressure-volume curve seems to be promising, ${ }^{12}$ but correct pressure-volume curve assessment is challenging because relatively complicated measurement of esophageal pressure is required, in addition to other measurements. ${ }^{16}$ Furthermore, Tal- mor et $\mathrm{al}^{13}$ established another way to optimize PEEP. They demonstrated that respiratory mechanics and oxygenation are improved by using directly measured transpulmonary pressure, resulting in the difference between the airway pressure and the esophageal pressure. ${ }^{13} \mathrm{How}$ ever, another study found that directly measured transpulmonary pressure is characterized by high inter-individual variability. Therefore, it can be considered a questionable method for PEEP setting. ${ }^{14}$ 


\section{Optimizing PEEP by EIT IN PoRcine ARDS}

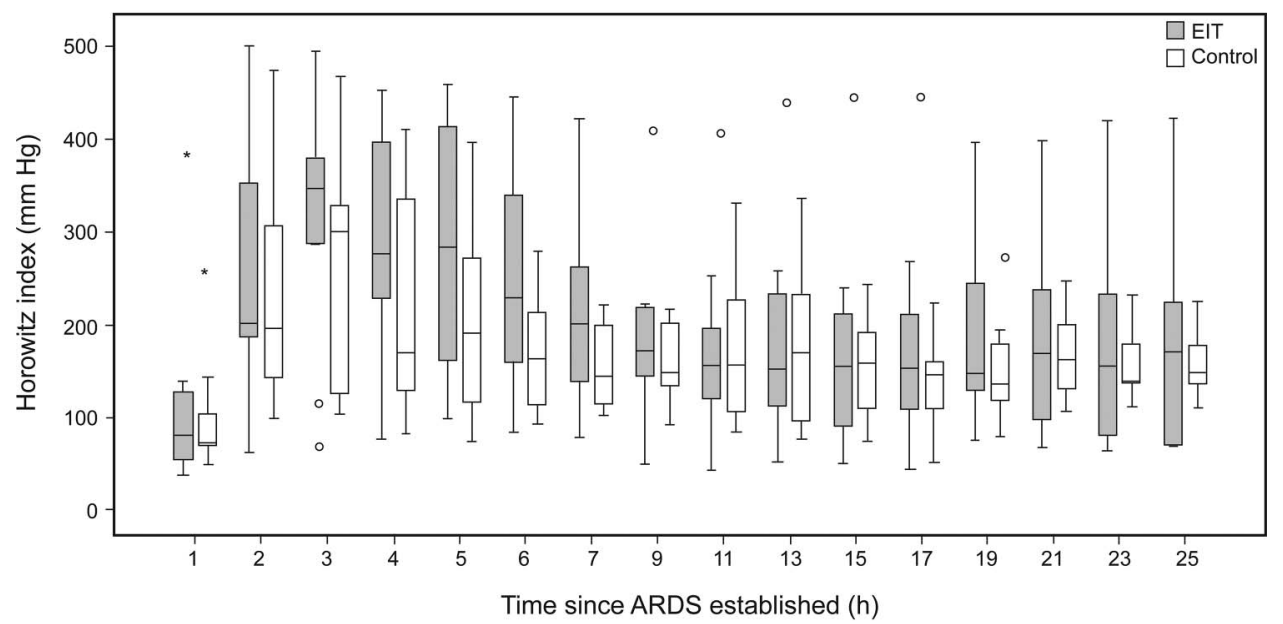

Fig. 4. Course of Horowitz index over the first $24 \mathrm{~h}$ after established ARDS. Analog to respiratory compliance, oxygenation was significantly impaired after ARDS and remained at a low level during the entire study period in both groups. Boxes represent interquartile ranges, and center lines denote the median. Whiskers show the highest and lowest values. Outliers are shown as points; extreme outliers are shown as stars. EIT = electrical impedance tomography.

Table 3. Respiratory and Hemodynamic Data

\begin{tabular}{|c|c|c|c|}
\hline Characteristics & EIT & Control & $P$ \\
\hline Compliance, $\mathrm{mL} / \mathrm{cm} \mathrm{H}_{2} \mathrm{O}$ & $8.94(8.55-10.07)$ & $9.44(8.38-10.06)$ & .80 \\
\hline $\mathrm{P}_{\mathrm{aO}_{2}} / \mathrm{F}_{\mathrm{IO}_{2}}$ & $171(106-219)$ & $149(103-210)$ & .73 \\
\hline PEEP, $\mathrm{cm} \mathrm{H}_{2} \mathrm{O}$ & $10(7-12)$ & $9(7-13)$ & .73 \\
\hline $\mathrm{P}_{\text {peak }}, \mathrm{cm} \mathrm{H}_{2} \mathrm{O}$ & $40.5(38.8-44.5)$ & $40(34.5-42.3)$ & .26 \\
\hline $\mathrm{P}_{\text {mean }}, \mathrm{cm} \mathrm{H}_{2} \mathrm{O}$ & $19(17.8-20.8)$ & $19(15.5-21.8)$ & .73 \\
\hline $\mathrm{S}_{\mathrm{pO}_{2}}, \%$ & $91(88-95)$ & $94(90-96)$ & .55 \\
\hline $\mathrm{F}_{\mathrm{IO}_{2}}, \%$ & $0.45(0.35-0.78)$ & $0.5(0.43-0.73)$ & .67 \\
\hline $\mathrm{P}_{\mathrm{aO}_{2}}, \mathrm{~mm} \mathrm{Hg}$ & $71(65.7-80.3)$ & $76.9(72.5-80.8)$ & .30 \\
\hline $\mathrm{P}_{\mathrm{aCO}_{2}}, \mathrm{~mm} \mathrm{Hg}$ & $48.9(43.9-58.8)$ & $55.1(50.9-60.3)$ & .09 \\
\hline Heart rate, beats/min & $125(104-130)$ & $114(99-153)$ & .73 \\
\hline $\mathrm{SAP}, \mathrm{mm} \mathrm{Hg}$ & $102(97-111)$ & 107 (99-109) & .67 \\
\hline MAP, $\mathrm{mm} \mathrm{Hg}$ & $77(70-83)$ & $82(77-83)$ & .44 \\
\hline DAP, $\mathrm{mm} \mathrm{Hg}$ & $59(53-67)$ & $66(58-67)$ & .49 \\
\hline
\end{tabular}

Results are median values over time after establishment of ARDS with corresponding interquartile ranges in parentheses.

EIT $=$ electrical impedance tomography

Compliance $=$ respiratory compliance

$\mathrm{P}_{\text {peak }}=$ peak airway pressure

$\mathrm{P}_{\text {mean }}=$ mean airway pressure

$\mathrm{S}_{\mathrm{pO}_{2}}=$ peripheral capillary oxygen saturation

$\mathrm{SAP}=$ systolic arterial pressure

$\mathrm{MAP}=$ mean arterial pressure

$\mathrm{DAP}=$ diastolic arterial pressure

Altogether, it is very difficult to talk about "optimal PEEP" today, since various competing methods coexist. Most approaches support better oxygenation, but they are accompanied by inflammatory processes due to overdistention and, consequently, a reduced long-term survival rate. In fact, overdistention is difficult to measure and monitor, especially in routine operations. Additionally, all methods of PEEP titration that are described above are based on measuring global lung mechanics.
By contrast, EIT is a bedside-available, noninvasive, and radiation-free tool that may be able to close the gap in the literature concerning PEEP optimization and the individualization of protective ventilation strategies by illustrating ventilation in smaller parts of the lung. EIT is able to estimate regional alveolar collapse and overdistention. ${ }^{31,32}$ In addition to standard circular electrode placement, diverse, more sophisticated electrode configurations have been studied, such as the attachment of internal elec- 


\section{Optimizing PEEP by EIT In PoRcine ARDS}

trodes to breathing and feeding tubes. ${ }^{33}$ Furthermore, several EIT-derived parameters seem to be very useful to optimize respiration therapy in clinical routines. One of these parameters is the impedance ratio, which examines eventual shifts of ventilation from dorsal to ventral parts or vice versa. ${ }^{30}$ To do so, the lung has to be sectioned into several regions of interest (at least into 2 horizontal layers). The so-called regional ventilation delay index is another well-described reasonable parameter, ${ }^{24}$ which demonstrates the relative delay of inflation time needed by respective regional impedance change exceeding a threshold. However, up until now, no study exists in either patients or animals that shows the benefits of regulating ventilation parameters by EIT in terms of clinical outcome parameters. ${ }^{29,34}$ Recently, different EIT parameters were introduced to find the best PEEP for optimizing ventilator therapy, some of them concerned with establishing homogeneity. Blankman et al ${ }^{35}$ optimized PEEP settings during a decremental PEEP trial in 12 post-cardiac surgery subjects by using the intratidal gas distribution index as a new homogeneity parameter, calculated by EIT. This index is the quotient of the intratidal gas distribution of the nondependent lung region and the intratidal gas distribution of the dependent lung region. In conclusion, the intratidal gas distribution index was able to indicate overdistention and was comparable with the dynamic compliance method. ${ }^{35}$ Up until now, studies using the intratidal gas distribution index for PEEP setting in ARDS lungs are still missing.

Another approach was introduced by Zhao et al ${ }^{30}$ in the form of the so-called global inhomogeneity index, which quantifies the heterogeneity of regional lung ventilation. However, in subjects with healthy lungs, the practice of setting PEEP as controlled by the global inhomogeneity index was not superior to the dynamic compliance method or the compliance volume curve approach. ${ }^{26}$ These methods pursue different approaches. Whereas the dynamic compliance and the compliance-volume curve method are based on the mechanics of respiratory system, the global inhomogeneity index illustrates the homogeneity of ventilation distribution. ${ }^{26}$ This implies that the global inhomogeneity index somehow reflects the pathological effects of mechanical ventilation. However, using the global inhomogeneity index solely to adjust PEEP in a porcine model of ARDS can lead to hyperdistension and barotrauma. ${ }^{27}$ Costa et al ${ }^{23}$ presented an EIT-derived parameter called the hyperdistension index for estimating hyperdistension based on regional lung mechanics.

In the present study, we investigated whether a combination of these 2 EIT-derived indices, the global inhomogeneity index and the hyperdistension index, is suitable to detect the optimal PEEP level. The study demonstrates that using EIT to set PEEP led to an individualized optimization of mechanical ventilation, providing hemodynamic stability. As expected, in the control group, the
PEEP levels show a strict dependence. High $\mathrm{F}_{\mathrm{IO}_{2}}$ levels are attended by high PEEP levels, and low $\mathrm{F}_{\mathrm{IO}_{2}}$ levels are associated with low PEEP levels. In the EIT group, no strict dependence between PEEP levels and $\mathrm{F}_{\mathrm{IO}_{2}}$ values is visible. Only a tendency of a combination of high PEEP levels and high $\mathrm{F}_{\mathrm{IO}_{2}}$ values, as well as low PEEP levels and low $\mathrm{F}_{\mathrm{IO}_{2}}$ values, is notable.

However, guiding the PEEP setting by EIT leads to different possible combinations of PEEP and $\mathrm{F}_{\mathrm{IO}_{2}}$. One potential explanation is the fact that some animals benefit from high PEEP levels because of resulting recruitment maneuvers, the consequence of which is to reduce $\mathrm{F}_{\mathrm{IO}_{2}}$ stepwise. In other animals, high PEEP levels did not have an effect on lung homogeneity or any other clinical advantage. Only a higher $\mathrm{F}_{\mathrm{IO}_{2}}$ delivered a better oxygenation. Gattinoni et al ${ }^{36}$ demonstrated that the percentage of potentially recruitable lung is variable in subjects with ARDS and may be important for PEEP setting. Briefly, these results demonstrate that EIT enables a more individual therapy.

There are several limitations that must be addressed before transferring our results to the clinical treatment of patients with ARDS. First, the investigation period lasted $24 \mathrm{~h}$. This is, with regard to ARDS therapy, a relatively short period. Mechanical ventilation in patients with ARDS must usually be performed for several days. Perhaps our approach with a more individualized PEEP setting will demonstrate more benefits after a longer observation period. Second, clinical end points for demonstrating a superiority of a new technology, such as mortality, ventilator-free days, organ dysfunction, stay in ICU, and stay in hospital, cannot be investigated in animal-based research projects but in clinical studies. Third, the ARDS network table, which is used in this study for PEEP titration in the control group, is not based on any functional assessment of lung aeration. Whereas the ARDS network study focused on ventilating with various tidal volumes, many other studies have dealt with optimal PEEP setting ${ }^{8,37-43}$ or concluded that the "open lung concept" in traumatized lungs seems to be beneficial. ${ }^{44}$ Hence, PEEP setting by the ARDS Network table is not the best approach and is not based on physiological facts but is easy to implement and therefore widely used and clinically established in intensive care medicine for many years. On the contrary, most methods for PEEP optimization are time-consuming and necessitate physiological measurements with additional tools or maneuvers. This was the reason for choosing the ARDS network table and EIT respectively. Fourth, in the EIT group, a step-wise PEEP titration was applied. On the one hand, this would be a relatively resource-consuming procedure in clinical practice; on the other hand, periodic incremental PEEP increases themselves may lead to recruitment effects. However, application of diverse PEEPs could be automatically performed by ventilators in the future. Fourth, 


\section{Optimizing PEEP by EIT IN PoRcine ARDS}

performing a PEEP trial may influence different outcome parameters. In fact, the global inhomogeneity index was higher in EIT group animals, whereas the impedance ratio was lower. Clinical interpretation of these results is speculative. A shift toward dorsal lung regions reflects recruitment effects, whereas a higher global inhomogeneity index indicates higher heterogeneity. However, reduced non-homogeneity and avoided overdistention (measured by the hyperdistension index) will potentially lead to better oxygenation in a longer investigation period by avoiding shear forces, toxic high concentrations of $\mathrm{F}_{\mathrm{IO}_{2}}$, and insufficient PEEP levels. The impedance ratio measures the ventilation distribution. A shift toward dorsal lung regions indicates recruitment, which has the potential to improve oxygenation and therefore also the clinical outcome. So, indeed, impedance ratio calculation might also be useful to guide ventilation therapy.

Finally, ventilator settings should be adaptive to individual disease stages and further patient-related factors. Therefore, currently established procedures must be optimized and developed. EIT is certainly one of the most promising techniques. Further studies, focusing more on individual ventilation, must be performed, including clinical outcome parameters.

In summary, PEEP setting by EIT could lead to an individualized approach that is noninvasive and available at bedside. In contrast, at the present time, routine practice requires periodic blood gas analyses for PEEP adjustment.

\section{Conclusions}

PEEP setting by EIT using a combination of the global inhomogeneity index and the hyperdistension index was clinically feasible and facilitated a more individual protective ventilation under stable hemodynamic conditions. Within a relatively short time period of $24 \mathrm{~h}$ after the induction of ARDS, no clinical differences occurred as compared with an established procedure using fixed tandem settings of $\mathrm{F}_{\mathrm{IO}_{2}}$ and PEEP.

Our findings, derived from an experimental study, suggest that optimal PEEP finding led by the observed individual response might make more sense than using a fixed regime. Whether this can be best achieved by the use of bedside EIT measures remains, however, still open for discussion.

\section{ACKNOWLEDGMENTS}

We thank the Institute for Laboratory Animal Science, RWTH Aachen University Hospital, Aachen, namely Prof. Tolba, Dr Scherer, and $\mathrm{Mr}$ Stopinski.

\section{REFERENCES}

1. Ashbaugh DG, Bigelow DB, Petty TL, Levine BE. Acute respiratory distress in adults. Lancet 1967;2(7511):319-323.
2. Villar J, Blanco J, Añón JM, Santos-Bouza A, Blanch L, Ambrós A, et al. The ALIEN study: incidence and outcome of acute respiratory distress syndrome in the era of lung protective ventilation. Intensive Care Med 2011;37(12):1932-1941.

3. Zambon M, Vincent JL. Mortality rates for patients with acute lung injury/ARDS have decreased over time. Chest 2008;133(5):11201127.

4. Matthay MA, Ware LB, Zimmerman GA. The acute respiratory distress syndrome. J Clin Invest 2012;122(8):2731-2740.

5. Plötz FB, Slutsky AS, van Vught AJ, Heijnen CJ. Ventilator-induced lung injury and multiple system organ failure: a critical review of facts and hypotheses. Intensive Care Med 2004;30(10):1865-1872.

6. Burns KE, Adhikari NK, Slutsky AS, Guyatt GH, Villar J, Zhang H, et al. Pressure and volume limited ventilation for the ventilatory management of patients with acute lung injury: a systematic review and meta-analysis. PloS One 2011;6(1):e14623.

7. The Acute Respiratory Distress Syndrome Network. Ventilation with lower tidal volumes as compared with traditional tidal volumes for acute lung injury and the acute respiratory distress syndrome. N Engl J Med 2000;342(18):1301-1308.

8. Briel M, Meade M, Mercat A, Brower RG, Talmor D, Walter SD, et al. Higher vs lower positive end-expiratory pressure in patients with acute lung injury and acute respiratory distress syndrome: systematic review and meta-analysis. JAMA 2010;303(9):865-873.

9. Goligher EC, Kavanagh BP, Rubenfeld GD, Adhikari NK, Pinto R, Fan E, et al. Oxygenation response to positive end-expiratory pressure predicts mortality in acute respiratory distress syndrome: a secondary analysis of the LOVS and ExPress trials. Am J Respir Crit Care Med 2014;190(1):70-76.

10. Suter PM, Fairley B, Isenberg MD. Optimum end-expiratory airway pressure in patients with acute pulmonary failure. N Engl J Med 1975;292(6):284-289.

11. Pintado MC, de Pablo R, Trascasa M, Milicua JM, Rogero S, Daguerre $\mathrm{M}$, et al. Individualized PEEP setting in subjects with ARDS: a randomized controlled pilot study. Respir Care 2013;58(9):14161423.

12. Amato MB, Barbas CS, Medeiros DM, Magaldi RB, Schettino GP, Lorenzi-Filho G, et al. Effect of a protective-ventilation strategy on mortality in the acute respiratory distress syndrome. N Engl J Med 1998;338(6):347-354.

13. Talmor D, Sarge T, Malhotra A, O'Donnell CR, Ritz R, Lisbon A, et al. Mechanical ventilation guided by esophageal pressure in acute lung injury. N Engl J Med 2008;359(20):2095-2104.

14. Chiumello D, Cressoni M, Colombo A, Babini G, Brioni M, Crimella $\mathrm{F}$, et al. The assessment of transpulmonary pressure in mechanically ventilated ARDS patients. Intensive Care Med 2014; 40(11):1670-1678.

15. Hess DR. Respiratory mechanics in mechanically ventilated patients. Respir Care 2014;59(11):1773-1794.

16. Hess DR. Recruitment maneuvers and PEEP titration. Respir Care 2015;60(11):1688-1704.

17. Frerichs I, Dargaville PA, Dudykevych T, Rimensberger PC. Electrical impedance tomography: a method for monitoring regional lung aeration and tidal volume distribution? Intensive Care Med 2003; 29(12):2312-2316

18. Marquis F, Coulombe N, Costa R, Gagnon H, Guardo R, Skrobik Y. Electrical impedance tomography's correlation to lung volume is not influenced by anthropometric parameters. J Clin Monit Comput 2006; 20(3):201-207.

19. Hinz J, Neumann P, Dudykevych T, Andersson LG, Wrigge H, Burchardi H, Hedenstierna G. Regional ventilation by electrical impedance tomography: a comparison with ventilation scintigraphy in pigs. Chest 2003;124(1):314-322. 


\section{Optimizing PEEP by EIT In PoRcine ARDS}

20. Hahn G, Sipinková I, Baisch F, Hellige G. Changes in the thoracic impedance distribution under different ventilatory conditions. Physiol Meas 1995;16(3 Suppl A):A161-A173.

21. Frerichs I, Dargaville PA, van Genderingen H, Morel DR, Rimensberger PC. Lung volume recruitment after surfactant administration modifies spatial distribution of ventilation. Am J Respir Crit Care Med 2006;174(7):772-779.

22. Markhorst DG, Groeneveld AB, Heethaar RM, Zonneveld E, Van Genderingen HR. Assessing effects of PEEP and global expiratory lung volume on regional electrical impedance tomography. J Med Eng Technol 2009;33(4):281-287.

23. Costa EL, Borges JB, Melo A, Suarez-Sipmann F, Toufen C Jr, Bohm SH, Amato MB. Bedside estimation of recruitable alveolar collapse and hyperdistension by electrical impedance tomography. Intensive Care Med 2009;35(6):1132-1137.

24. Wrigge H, Zinserling J, Muders T, Varelmann D, Günther U, von der Groeben $\mathrm{C}$, et al. Electrical impedance tomography compared with thoracic computed tomography during a slow inflation maneuver in experimental models of lung injury. Crit Care Med 2008;36(3):903909.

25. Lowhagen K, Lundin S, Stenqvist O. Regional intratidal gas distribution in acute lung injury and acute respiratory distress syndromeassessed by electric impedance tomography. Minerva Anestesiol 2010;76(12):1024-1035.

26. Zhao Z, Steinmann D, Frerichs I, Guttmann J, Möller K. PEEP titration guided by ventilation homogeneity: a feasibility study using electrical impedance tomography. Crit Care 2010;14(1):R8.

27. Czaplik M, Biener I, Leonhardt, S, Rossaint R. Setting ventilation parameters guided by electrical impedance tomography in an animal trial of acute respiratory distress syndrome. Proc SPIE 9038, medical imaging 2014: biomedical applications in molecular, structural, and functional imaging. doi: 10.1117/12.2043402.

28. Wang HM, Bodenstein M, Duenges B, Ganatti S, Boehme S, Ning $\mathrm{Y}$, et al. Ventilator-associated lung injury superposed to oleic acid infusion or surfactant depletion: histopathological characteristics of two porcine models of acute lung injury. Eur Surg Res 2010;45(3): 121-133.

29. Zhao Z, Möller K, Steinmann D, Frerichs I, Guttmann J. Evaluation of an electrical impedance tomography-based global inhomogeneity index for pulmonary ventilation distribution. Intensive Care Med 2009;35(11):1900-1906.

30. Kunst PW, Vazquez de Anda G, Böhm SH, Faes TJ, Lachmann B, Postmus PE, de Vries PM. Monitoring of recruitment and derecruitment by electrical impedance tomography in a model of acute lung injury. Crit Care Med 2000;28(12):3891-3895.

31. Costa EL, Lima RG, Amato MB. Electrical impedance tomography. Curr Opin Crit Care 2009;15(1):18-24.

32. Bikker IG, Leonhardt S, Reis Miranda D, Bakker J, Gommers D. Bedside measurement of changes in lung impedance to monitor alveolar ventilation in dependent and non-dependent parts by electrical impedance tomography during a positive end-expiratory pressure trial in mechanically ventilated intensive care unit patients. Crit Care 2010;14(3):R100
33. Czaplik M, Antink CH, Rossaint R, Leonhardt S. Application of internal electrodes to the oesophageal and tracheal tube in an animal trial: evaluation of its clinical and technical potentiality in electrical impedance tomography. J Clin Monit Comput 2014;28(3):299-308.

34. Pomprapa A, Schwaiberger D, Pickerodt P, Tjarks O, Lachmann B, Leonhardt S. Automatic protective ventilation using the ARDSNet protocol with the additional monitoring of electrical impedance tomography. Crit Care 2014;18(3):R128.

35. Blankman P, Hasan D, Erik G, Gommers D. Detection of "best" positive end-expiratory pressure derived from electrical impedance tomography parameters during a decremental positive end-expiratory pressure trial. Crit Care 2014;18(3):R95.

36. Gattinoni L, Caironi P, Cressoni M, Chiumello D, Ranieri VM, Quintel M, et al. Lung recruitment in patients with the acute respiratory distress syndrome. N Engl J Med 2006;354(17):1775-1786.

37. Kacmarek RM, Villar J, Sulemanji D, Montiel R, Ferrando C, Blanco $\mathrm{J}$, et al. Open lung approach for the acute respiratory distress syndrome: a pilot, randomized controlled trial. Crit Care Med 2016; 44(1):32-42.

38. Villar J, Kacmarek RM, Pérez-Méndez L, Aguirre-Jaime A. A high positive end-expiratory pressure, low tidal volume ventilatory strategy improves outcome in persistent acute respiratory distress syndrome: a randomized, controlled trial. Crit Care Med 2006;34(5): 1311-1318.

39. Badet M, Bayle F, Richard JC, Guérin C. Comparison of optimal positive end-expiratory pressure and recruitment maneuvers during lung-protective mechanical ventilation in patients with acute lung injury/acute respiratory distress syndrome. Respir Care 2009;54(7): 847-854.

40. Chiumello D, Cressoni M, Carlesso E, Caspani ML, Marino A, Gallazzi E, et al. Bedside selection of positive end-expiratory pressure in mild, moderate, and severe acute respiratory distress syndrome. Crit Care Med 2014;42(2):252-264.

41. Meade MO, Cook DJ, Guyatt GH, Slutsky AS, Arabi YM, Cooper DJ, et al. Ventilation strategy using low tidal volumes, recruitment maneuvers, and high positive end-expiratory pressure for acute lung injury and acute respiratory distress syndrome: a randomized controlled trial. JAMA 2008;299(6):637-645.

42. Phoenix SI, Paravastu S, Columb M, Vincent JL, Nirmalan M. Does a higher positive end expiratory pressure decrease mortality in acute respiratory distress syndrome? A systematic review and meta-analysis. Anesthesiology 2009;110(5):1098-1105.

43. Brower RG, Lanken PN, MacIntyre N, Matthay MA, Morris A, Ancukiewicz M, et al. Higher versus lower positive end-expiratory pressures in patients with the acute respiratory distress syndrome. N Engl J Med 2004;351(4):327-336.

44. Schreiter D, Reske A, Stichert B, Seiwerts M, Bohm SH, Kloeppel $\mathrm{R}$, Josten C. Alveolar recruitment in combination with sufficient positive end-expiratory pressure increases oxygenation and lung aeration in patients with severe chest trauma. Crit Care Med 2004;32(4): 968-975. 